\title{
Expression of Measles Virus RNA in Peripheral Blood Mononuclear Cells of Patients with Measles, SSPE, and Autoimmune Diseases
}

\author{
S. SCHNEIDER-SCHAULIES, H. W. KRETH, ${ }^{1}$ G. HOFMANN, ${ }^{1}$ M. BILLETER, ${ }^{2}$ AND V. TER MEULEN ${ }^{3}$ \\ Institut für Virologie und Immunbiologie, Universităt Wurzburg, Versbacher Strasse 7, D-8700 Würburg, Germany
}

Received November 8, 1990; accepted February 20, 1991

\begin{abstract}
In order to characterize measles virus (MV) infection in peripheral blood mononuclear cells (PBMCs), RNA was isolated from PBMCs after PHA-stimulation for $72 \mathrm{hr}$ of 9 patients with acute measles, 16 patients with subacute sclerosing panencephalitis (SSPE), 13 patients with various autoimmune diseases, and 16 healthy control donors. The RNA obtained was screened for the presence of MV N (nucleocapsid) gene specific transcripts of either positive or negative orientation in a S1 nuclease protection assay. The sensitivity of this assay allowed us to detect one infected cell in 20,000 PBMCs or 0.1 to 0.05 copies of MV-specific RNA per cell. Using single-stranded DNA or RNA probes expression of MV genomic RNA of negative polarity could be detected in only one case of acute measles and one healthy control donor. Conversely, $\mathrm{N}$-specific transcripts of positive polarity, indicating active transcription, could only be detected in patients with acute measles. In addition, in infected PBMCs and in a persistently MV-infected B cell line positive stranded $\mathrm{N}$-specific transcripts containing leader usually present at very low frequency have been found in relatively increased amounts in comparison with transcripts lacking leader. Whereas the ratio of these RNA species during lytic infection with MV in Vero cells is about 1:50, the ratio found here ranges from $1: 3$ to $1: 10$. This altered ratio indicates a specific regulation of MV specific transcription in cells of lymphoid origin that has not been found in any other cell system analyzed. (3) 1991 Academic Press, Inc.
\end{abstract}

\section{INTRODUCTION}

Measles virus (MV) is the etiological agent for some acute and chronic diseases of man. During the acute infection the virus reveals a strong predilection to infect cells of lymphoid origin. MV can be isolated from peripheral blood monocuclear cells (PBMCs) and viral antigens as well as virus-specific RNA can be detected in these cell populations (Gresser et al., 1963; Hyypia et al., 1988). In vitro, $M V$ efficiently infects established $B$ or T cell lines, whereas in PBMCs a "silent infection" occurs with the expression of MV antigens and release of infectious virus upon mitogen stimulation (Joseph et al., 1975; Lucas et al., 1978). In addition, impairment of cell mediated and humoral immune functions in acute measles and tissue culture could be observed (for review, see Casali et al., 1989; McChesney and Oldstone, 1989).

Based on these observations studies have been carried out in order to characterize MV infection in lymphocytes not only in acute measles but also in other

\footnotetext{
1 Universităts-Kinderklinik, Josef-Schneider-Str. 2, D-8700 Wurzburg, Germany.

2 Institut fur Molekularbiologie I der Universitắt Zurich, Eidgenossische Technische Hochschule, Honggerberg, CH-8093 Zurich, Switzerland.

${ }^{3}$ To whom requests for reprints should be addressed.
}

MV-associated diseases. In subacute sclerosing panencephalitis (SSPE) either MV antigens or RNA have been detected by some groups in PBMCs of patients with this disease in the absence of any major alteration of the immune response (Horta-Barbosa, 1979; Wrosz et al., 1979; Fournier et al., 1985, 1988). In chronic active hepatitis, in systemic lupus erythematosis and in glomerulonephritis as well as in healthy controls unconfirmed reports describe the presence of MV specific RNA by dot blot or in situ hybridization in PBMCs of these patients suggesting that MV may persist in lymphoid cells after acute measles and is not cleared by the host defence mechanism (Robertson et al., 1987; Andjaparidze et al., 1989).

The possibility that MV may persist in PBMCs is of general interest not only in the context of life-long immunity against this virus but also in relation to the pathogenesis of SSPE and certain autoimmune diseases. Therefore, detailed studies implicating techniques of molecular biology are now needed to determine the state of MV-lymphocyte interactions. In the present investigation we analyzed PBMCs from healthy adult control donors, patients with acute measles, SSPE, and various autoimmune diseases for the presence of $\mathrm{MV}$-specific transcripts, applying a liquid hybridization assays by using single-stranded $\mathrm{N}$ gene specific hybridization probes. By this method we could achieve quantifications for the transcription of 
genomic and subgenomic MV-specific RNAs and additionally provide some information about transcriptional regulation of $M V$ in PBMCs.

\section{MATERIALS AND METHODS}

\section{Cells and virus}

Vero cells were grown in MEM containing 5\% FCS; EBV-transformed B-cells (BLCL) and persistently MVLEC-infected BLCL-cells (WE-LEC) were grown in RPMI 1640 containing 15\% FCS. Peripheral blood mononuclear cells (PBMCs) were obtained by Ficoll/ Paque separation of heparinized peripheral blood from patients with acute measles (9 samples), SSPE (16 samples), systemic lupus erythematosis (6 samples), various autoimmune diseases $(7$ samples), healthy young adults (16 samples), and newborn nonvaccinated individuals (2 samples), and from umbilical cord material (2 samples). The diagnoses were documented by clinical, serological or electroencephalographic findings. After isolation, cells were either frozen at $-70^{\circ}$ or used directly as fresh material. Stimulation was performed in RPMI 1640 containing 10\% FCS in the presence of $10 \mu \mathrm{g} / \mathrm{ml}$ PHA for $72 \mathrm{hr}$. The Edmonston strain of measles was passaged and titrated in Vero cells. Infections were performed for $48 \mathrm{hr}$ at an input multiplicity of 0.1 .

\section{Patients}

SSPE. Sixteen samples from patients of stages I-III. Serum titers (HHT) of 13 patients were between $1: 1024$ and 1:4096, of 1 patient 1:512, and of 2 patients 1:256. CSF titers ranged from 1:8 to $1: 128$.

Acute measles. Eight samples of patients at different times of exanthema with serum titers of 1:32 in the first days of exanthema to $1: 512$ at late stages (mean titer $1: 128)$.

Healthy controls. Samples from healthy adult donors were derived from an age group of about 24-30 years with serum titers ranging from $1: 32$ to $1: 256$. All of them had a history of acute measles. Negative controls were derived from two newborn individuals (no detectable titer in HHT) and umbilical cord lymphocytes.

Autoimmune diseases. Samples were obtained from 6 patients with SLE, 2 patients with pemphigoides bullosa, one patient with pemphigoides vulgaris, one patient with dermatomyositis, one patient with linear IgAdermatosis, one patient with Sjögren syndrome and one patient with questionable autoimmune disease.

\section{Extraction of RNA}

RNA extraction from cultured cells was performed as described previously by lysis in guanidinium thiocya- nate buffer and subsequent centrifugation through $\mathrm{CsCl}$ gradients (Schneider-Schaulies et al., 1989). In general, the amounts of total RNA obtained from PHAexpanded PBMCs were about $10 \mu \mathrm{g}$ from $10^{7}$ cells. This value corresponds to $1 \mathrm{pg}$ RNAvcell, which is about 10 times less than for Vero cells.

\section{Plasmid DNAs}

Probes used for hybridization analyses were derived from the 3 '-end of the genome and contained the 185bp Pstl/BamHI fragment (nt $0-185$ ) in M13 or pSP6 vectors (M13 mp 9/32 or pSP64MV3S, respectively; including linker sequences, the size of the cloned fragment was about $260 \mathrm{bp}$; for detailed description, see also legend to Fig. 1c) or the 420-bp BamHI/Pstl fragment (pSP65MV3L or PSP64MV3L, respectively; detailed description in Fig. 3b) (nt 185-605).

\section{S1 nuclease protection analysis}

S1 nuclease protection assays were performed as described previously (Billeter et al., 1984). Briefly, M13 probes were labeled by primer extension in the presence of ${ }^{32} \mathrm{P}$ ]dATP and subsequently gel purified (Sambrook et al., 1989). The probes were hybridized to samples of total RNA in an $80 \%$ formamide containing hybridization buffer in a total volume of $30 \mu$ at $45^{\circ}$ for 16 $\mathrm{hr}$. Nuclease digestion was performed in a total volume of $300 \mu \mathrm{l} 1 \times \mathrm{S} 1$ buffer containing $700 \mathrm{U} / \mathrm{ml}$ nuclease $\mathrm{S} 1$ (Pharmacia Fine Chemicals) for $45 \mathrm{~min}$ at $30^{\circ}$. The digestion was followed by deproteinization with proteinase $K$ and subsequent phenol extraction. Following precipitation, samples were separated on $8 \%$ sequencing gels. The same protocol for the nuclease protection assay was used for the labeled transcripts derived from the pSp6 vectors (Melton et al., 1984; [ $\left.{ }^{32} \mathrm{P}\right] \mathrm{CTP}, 410 \mathrm{Ci} / \mathrm{mmol}$, Amersham-Buchler). The transcription vector used (pSP65MV3L) was linearized by Pvull digestion in order to elongate the probe. Quantification of the signals was obtained by excising the appropriate bands from the gels followed by scintillation counting. Copy numbers were determined by dividing the total amount of radioactivity incorporated in specific bands (following subtraction of the counts corresponding to the background of each lane) divided by the number of counts incorporated per molecule of probe. The calculation was performed as follows: 0.4 $\mu \mathrm{Ci} / \mathrm{pmol}$ (specific activity of $\left.{ }^{32} \mathrm{P}\right] \mathrm{CTP}$ ) $\times 2.2 \times 10^{6}$ $(\mathrm{cpm} / 1 \mu \mathrm{Ci})=8.8 \times 10^{5} \mathrm{cpm} / \mathrm{pmol} ; 8.8 \times 10^{5}$ divided by $6 \times 10^{11}$ (corresponding to $1 \mathrm{pmol}$ of molecules) revealed the number of $\mathrm{cpm} / \mathrm{molecule}$ CTP. This quotient was multiplied by the number of $\mathrm{C}$-residues contained in the individual probe (for example, the $420-b p$ fragment would contain $105 \mathrm{C}$-residues, revealing 1.2 
$\times 10^{-4} \mathrm{cpm} /$ copy of the probe). The calculated total copy numbers were divided by the amount of RNA applied to the individual hybridization reaction (usually 5 $\mu g$ of RNA) and standardized to yield the value of "copy number per 10 pg RNA."

\section{Northern blot analysis}

RNA analyses were performed as described (Schneider-Schaulies et al., 1989), Northern blots were hybridized to the labeled M13 single-stranded DNA at $48^{\circ}$ in $50 \%$ formamide for $16 \mathrm{hr}$ and subsequently washed in $0.2 \times$ SSC, $0.2 \%$ SDS at $70^{\circ}$.

\section{RESULTS}

\section{The sensitivity of the methods applied}

In order to determine the sensitivity of our detection systems, control experiments with Northern blots and nuclease $S 1$ protection assays were performed. Synthetic RNA transcripts of the pSP64MV3s N-specific clone (Fig. 1C) were serially diluted with total RNA extracted from uninfected Vero cells. The mixtures were either separated on a formaldehyde containing agarose gel and probed with the labeled ssDNA M13 clone (mp9/32) containing negative stranded sequences corresponding to the $3^{\prime}$-end of the MV genomes (Fig. 1c) or subjected to liquid hybridization in a nuclease $S 1$ protection assay.

Using the Northern blot analysis specific hybridization could be detected down to 1 copy/infected cell (calculated as $10 \mathrm{pg}$ of total RNA for Vero cells) (not shown). The nuclease $S 1$ analysis was at least 10 times as sensitive because specific signals could be detected down to $0.1 \mathrm{copy} / \mathrm{cell}$ (Fig. 1a, lane 7). In lane 8 (representing 0.01 copy/cell), a faint specific signal could be detected as well almost at the background level (barely visible in the figure). Smaller bands represent artifacts due to the nuclease digestion. By performing the same analysis using a labeled RNA transcript of negative polarity as hybridization probe in a nuclease $\$ 1$ protection assay, no increased sensitivity could be found under our experimental conditions (not shown).

In a second set of experiments, persistently MV-LEC infected $B$ cells were serially diluted with uninfected $B$ cells, RNA was extracted and subjected to nuclease S1 protection assay using the M13 probe (mp 9/32; Fig. 1c) specific for the plus strand transcripts containing leader and $\mathrm{N}$-gene sequences. Total control RNA from Vero cells lytically infected with MV revealed clear signals for the protected fragments corresponding to the 185-nt leader-containing and 120-nt leader-free $\mathrm{N}$ gene-specific transcripts at a ratio of about 1:50 (Fig. 1b, lane 3, and Fig. 1c). Conversely, the ratio between leader-containing and leader-free $\mathrm{N}$-specific transcripts in the persistently infected B-cells appeared to be altered in favor of the leader-containing sequences (ratio about 1:3; Fig. 1b, lane 5; Table 1). Signals corresponding to the N-specific 120-nt fragment could be visualized down to a dilution of one infected cell in 20,000 (Fig. 1b, lane 6). The persistently infected Bcells contain about 2000 copies of the $\mathrm{N}$ mRNA $10 \mathrm{pg}$ RNA (representing about 10 cells) as determined by Northern blots containing synthetic RNAs as internal standards, as described elsewhere (Cattaneo et al., 1987) (not shown). Thus, the detection limit of the method ranges around 0.1 copy/10 pg RNA or 0.01 copy/cell. The slightly lower sensitivity is probably due to the concurrent hybridization of labelled transcripts with viral negative-stranded transcripts present in the hybridization reaction containing total RNA from lytically infected cells. Under our experimental conditions the sensitivity of the protection assay was at least 10 to 20 times higher than that of the Northern blot. For this reason, nuclease protection assays were chosen for further experiments.

\section{Nuclease protection analysis of $\mathrm{N}$-gene specific transcripts of positive polarity in PBMCs from patients with acute measles, SSPE, or autoimmune diseases and healthy control donors}

PHA-stimulated PBMCs from peripheral blood were used either after storage by freezing or as freshly obtained material. Total RNA was prepared from up to $10^{7}$ cells/sample (yielding about $10 \mu \mathrm{g}$ total RNA, see also Materials and Methods) and hybridized to the ${ }^{32} \mathrm{P}$-labeled M13 ssDNA corresponding to the $3^{\prime}$ end sequence of the genome (Fig. 1C). In RNA samples derived from healthy adult control donors (16 specimen were analyzed), no signals specific for leader-containing or leader-free $\mathrm{N}$-gene sequences of positive orientation were detected (representative in Fig. 2, lane 3) except in one case of a laboratory worker handling MV (not shown), where the expression rates of the $\mathrm{N}$-genespecific transcripts reached levels as in patients with acute measles. Negative results were also obtained in all RNA samples isolated from PBMCs of patients with SSPE ( 16 samples) and autoimmune diseases ( 13 samples) (representative in Fig. 2, lanes 7 and 8). By contrast, RNA from PBMCs of patients with acute measles revealed signals specific for both leader-containing and leader-free $\mathrm{N}$-specific transcripts (Fig. 2, lanes 5 and 6). Interestingly, the signals for the leader-containing RNAs were relatively strong in relation to those for the subgenomic transcripts lacking the leader sequence (Fig. 2, lanes 5 and 6) exactly as previously 
a

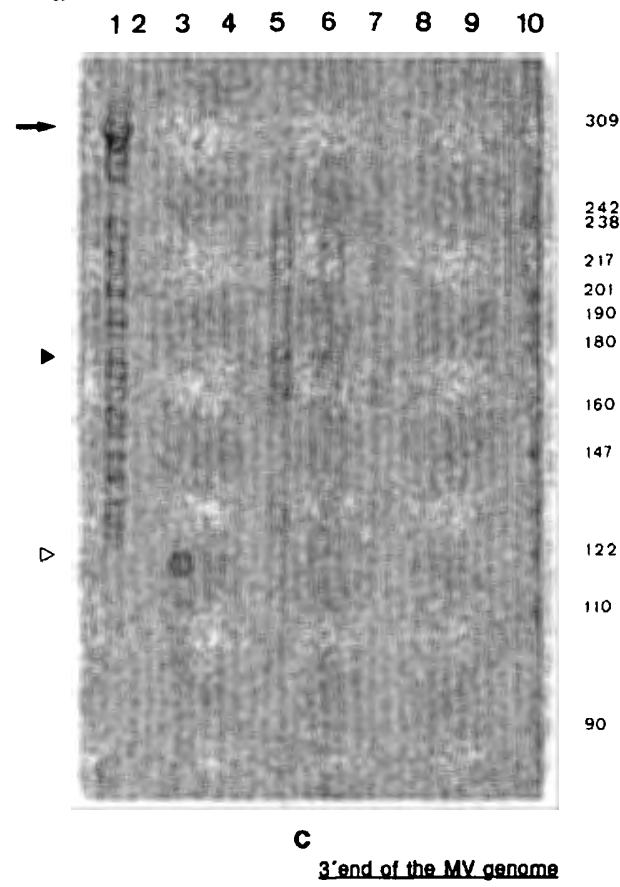

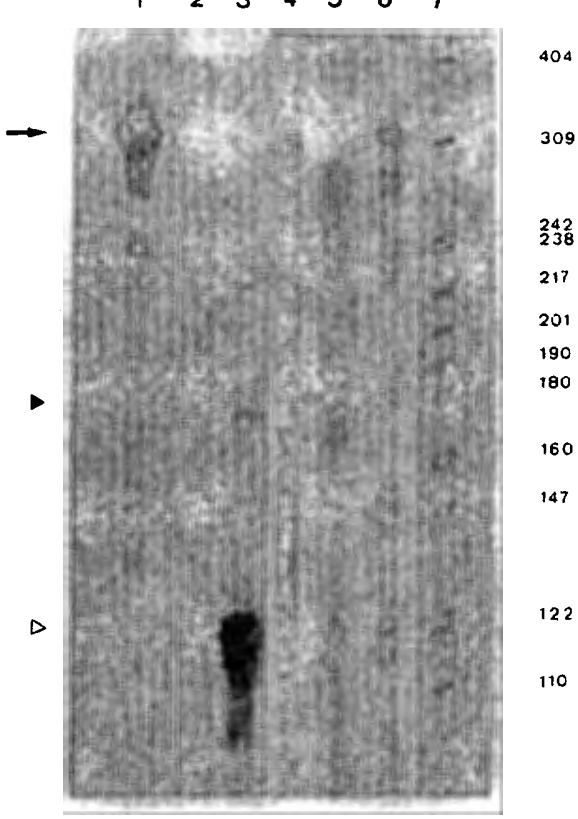

185

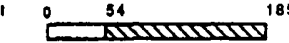

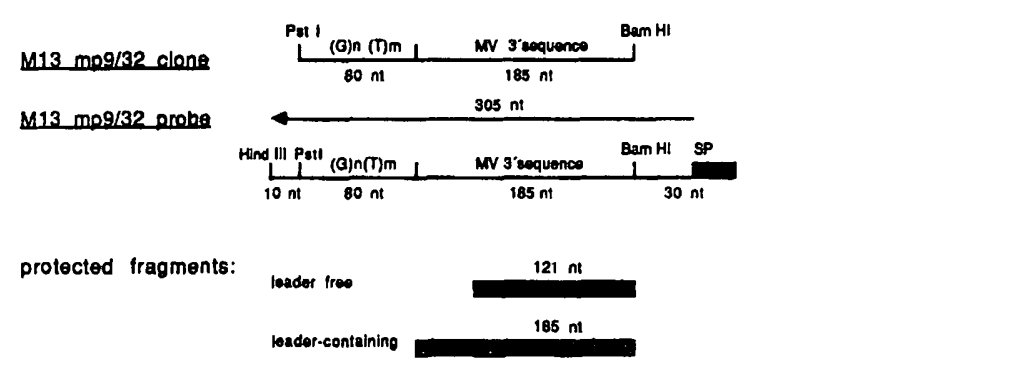

DSP64MV3s

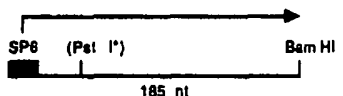

Fig. 1. Determination of the sensitivity of the methods applied. (a) A RNA transcript complementary to the $3^{\prime}$-end of the genome was transcribed from the PSP64MV3s vector (the MV-specific cDNA fragment is shown in (c)), total amount synthesized determined by the incorporation of trace amounts of [32P]CTP. Serial dilutions with total RNA from uninfected Vero cells were analysed by nuclease $\$ 1$ protection assay using a complementary single-stranded [ ${ }^{32}$ P]dATP-labelled DNA (M13 mp 9/32; see (c)) as hybridisation probe: Lane 1, hybridization probe undigested; lane 2, probe digested with S1-nuclease; lane 3, probe hybridized to $1 \mu \mathrm{g}$ of RNA from lytically infected Vero cells and, lane 4, to $1 \mu \mathrm{g}$ of RNA trom uninfected Vero cells; lanes 5-10, diluted synthetic transcript representing 5 copies (lane 5), 1 copy (lane 6), 0.1 copy (lane 7), 0.01 copy (lane 8), and 0.001 copy (lane 9) per cell (10 pg RNA) in a total amount of $5 \mu \mathrm{g}$ RNA. As a marker, end-labeled pBR322/Hpall-digested DNA was used (lane 10). (b) Lane 1, undigested probe; lane 2, probe hybridized to $5 \mu \mathrm{g}$ RNA of uninfected; lane 3, $1 \mu \mathrm{g}$ RNA of MV-Edm-infected Vero cells; lane $4,5 \mu \mathrm{g}$ RNA of uninfected BLCL-cells; lanes 5 and 6 . RNA from persistently infected WE-LEC cells diluted with uninfected BLCL-cells to a ratio of 1 infected cell in 10,000 (lane 5) or 20,000 (lane 6) in a final amount of $5 \mu \mathrm{g} \mathrm{RNA;} \mathrm{lane} \mathrm{7,} \mathrm{the} \mathrm{same} \mathrm{marker} \mathrm{as} \mathrm{in} \mathrm{(a).} \mathrm{In} \mathrm{(a)} \mathrm{and} \mathrm{(b)} \mathrm{the}$ positions of the probe (arrow), the leader-containing (black triangle) and the leader-free subgenomic transcript (open triangle) are indicated. For optimal documentation, the X-rays had to be cut and remounted. (c) Localization of the probes used within the MV genome and the protected fragments following nuclease digestion. On the top of (c), the $3^{\prime}$ end of the MV genome containing a 54-bp-long noncoding leader sequence ( $\mathrm{nt}$ $0-54$, open box) and the first $121 \mathrm{nt}$ of the $\mathrm{N}$-gene coding sequence are indicated (nt 54-185, hatched box). The CDNA clone (M13 mp 9/32 clone) used as labeled probe encompasses this particular 185-nt-long MV-specific sequence and, additionally, an about 80-nt-long (G)n(T)m linker that was introduced during the cloning procedure, together revealing a total length of $260 \mathrm{bp}$. Due to the labeling procedure, the $260-\mathrm{bp}$ clone was further elongated at its $3^{\prime}$ '-end by about $30 \mathrm{nt}$ (including the sequencing primer, SP) and by $10 \mathrm{nt}$ at its 5 '-end by restriction enzyme digestion following primer extension to yield a total probe length of $305 \mathrm{nt}$ (see (a) and (b). lane 1). The expected protected fragments following nuclease digestion are indicated as the 121-nt-long leader-free and the 185-nt-long leader-containing transcript. For the transcription of the 
observed in the persistently infected B-cells (Fig. 1b, lane 5) and in contrast to the lytically infected Vero cells (Fig. 2, lane 4; lanes 3 of Figs. 1a and 1b). By quantification of all signals for the $\mathrm{N}$-specific transcripts detected in RNA from PBMCs, leader-free transcripts proved to be only 3 - to 10 -fold more abundant than the leader-containing counterparts, whereas in lytically infected Vero cells this ratio was at least 50:1 (Table 1). Quantification of the signals obtained revealed that the two kinds of transcripts were expressed at variable amounts in the individual samples (Table 1). For the leader-free transcript, expression rates from 0.1 to 40 copies/pg RNA (representing the average amount of total RNA in lymphocytes) were found in PBMCs from patients with acute measles. It should be kept in mind, however, that an augmentation of MV specific sequences could have occurred as a consequence of the preceding PHA-stimulation of the cultures. A correlation between the stage of the disease (indicated as day of exanthema d.e.) and the expression rate of viral transcripts could not be found (Table 1).

\section{Expression of genomic RNA transcripts in PBMCs}

Since N-gene-specific sequences of positive polarity are unequivocally detectable only in the RNA samples of PBMCs from patients with acute measles we looked for the presence of MV-specific genomic RNA sequences in samples of total RNA by using a labeled RNA probe complementary to a region close to the $3^{\prime}$ end of the genome (pSP65MV3L) (Fig. 3b). An RNA probe was chosen because of the higher stability of RNAVRNA in comparison to RNAVDNA hybrids and the possibility to obtain a large quantity of probe able to compete out the excess of unlabeled positive stranded transcripts. The signal at position 622 in all lanes corresponds to the position of the undigested probe (Fig. 3, lane 1) that has not been digested completely in lanes 2-18. As negative controls, RNA from PBMCs of nonvaccinated newborn children and umbilical cord lymphocytes were used (Fig. 3, representative in lane 3). As positive controls for the hybridization, either the antisense transcript to the labeled probe (Fig. 3, lane 2) or minus PA-RNA from an SSPE brain (Fig. 3, lane 4) were analyzed.

Signals for protected fragments of the expected size $(420 \mathrm{bp})$ were clearly detectable in the RNA of PBMCs from one patient with acute measles (lane 10) and the same healthy control donor who had also responded to probes of the opposite polarity, a technician in our labo- ratory working with MV (lane 16). In all other samples tested, very faint signals not clearly discernible from background were obtained representing possibly MV RNA at a concentration which did not allow us to confirm its specificity (representative in lanes 5-9 for the SSPE patients, in lanes 11-13 for patients with acute measles, in lanes 14 and 15 for the healthy control donors, and in lanes 17 and 18 for patients with autoimmune diseases). PBMCs from one patient with acute measles were obtained at the first day of rash (lane 10), and 11 days later (lane 11) when the signal intensity markedly dropped to the level of the other samples analyzed. The signal observed in lane 18 (PBMCs from a patient with SLE) did not correspond exactly to the electrophoretic mobility expected and seen in the other lanes. Therefore it was considered as clearly nonspecific. No major differences in signal intensities could be detected except for the two cases described above (lane 10 and 16). The obviously slightly different electrophoretic mobility of the specific signal in lanes 2-9 and lanes $10-17$ is due to the fact that the protected fragments were separated on two gels that were mounted together for the documentation.

By quantification of the signals obtained the amounts of MV-specific transcripts within the total cell population analyzed could be calculated. Expression frequencies were determined at 0.06 copies of genomic RNA per cell for the healthy control (Fig. 3, lanes 16) and at 2 copies per cell for the patient with acute measles. Since the signals for the majority of all other samples tested were at or even beyond our detection limit (see Figs. $1 \mathrm{a}$ and $1 \mathrm{~b}$ ) they would contain less than 0.05-0.01 copies of MV genomic RNA per cell if these signals were specific.

\section{DISCUSSION}

Persistent infections of measles virus of lymphoid tissue have been of interest in the context of lifelong immunity, in the etiology of autoimmune diseases and CNS infections (Fournier et al., 1985, 1988; Robertson et al., 1987; Anjaparidze et al., 1989). In particular, in SSPE and MIBE (measles inclusion body encephalitis) persistently infected lymphocytes could play an important pathogenic role since measles virus could be transported by such cells to the CNS and initiate a persistent infection. If this would occur the great variability in the incubation period observed between acute

synthetic RNA complementary to the probe, the pSP64MV3s cDNA clone was used. In the multiple cloning site of the pSP64 vector the 185-nt-long MV-specific sequence (nt 0-185) lacking the 80-nt (G)n(T)m linker sequences was cloned (Since the Pstl site used for cloning into the vector did not correspond to the Pstl site in the original clone $5^{\prime}$ to the linker sequence it is indicated as (Pst $\left.{ }^{*}\right)$ ). Transcription from the SP6 promoter revealed a transcript covering the $3^{\prime}-\mathrm{MV}$-specific sequence in positive orientation complementary to the probe used. 
TABLE 1

Positive Strand N-Gene-Specific Transcripts in PBMCs of patients With acute Measles, SSPE, Autoimmune Diseases, AND HEALTHY CONTROLS

\begin{tabular}{|c|c|c|c|c|}
\hline RNA samples & & $\begin{array}{l}\text { Leader-free } \\
\text { transcript }\end{array}$ & $\begin{array}{l}\text { Leader-containing } \\
\text { transcript }\end{array}$ & Ratio \\
\hline $\begin{array}{l}\text { SSPE }(1-16) \\
\text { autoimmune dis. }\end{array}$ & & ND & ND & - \\
\hline$(1-13)$ & & ND & ND & 一 \\
\hline controls $(1-15)$ & & ND & ND & 一 \\
\hline$(16)$ & & $5 c$ & $2 c$ & $1: 3$ \\
\hline acute measles & d.e. & & & \\
\hline$A+$ & 1 & $50 c$ & $15 c$ & $1: 3$ \\
\hline B+ & 11 & $5 c$ & ND & - \\
\hline $\mathrm{C}$ & 3 & $5 c$ & ND & - \\
\hline D & $2-3$ & $2 c$ & ND & - \\
\hline$E$ & $3-4$ & $1 \mathrm{c}$ & ND & 一 \\
\hline$F$ & 7 & $10 c$ & $3 c$ & $1: 3$ \\
\hline$G^{*}$ & 3 & $80 c$ & $25 c$ & $1: 3$ \\
\hline $\mathrm{H}^{*}$ & $2-3$ & $400 \mathrm{c}$ & $40 c$ & $1: 10$ \\
\hline 1 & 10 & $2 c$ & ND & - \\
\hline Vero control & - & $20000 \mathrm{C}$ & $400 \mathrm{c}$ & $1: 50$ \\
\hline
\end{tabular}

Note. Signals for leader-containing and leader-free N specific transcripts obtained in nuclease protection assays as shown in Fig 2. were quantified by excising the corresponding gel slices and determined by scintillation counting. The copy number of probe contained in each individual signal was determined on the basis of the radioactivity incorporated per copy of probe. The values indicated as " $c$ " have been achieved by distributing the calculated copy numbers of probe to $10 \mathrm{pg}$ RNA representing the total amount of RNA of one Vero cell and of about 10 PBMCs, respectively. ND, not detectable; + indicates that the two samples analyzed were derived from the same patient on different days of exanthema (d.e.); "RNA analysis is shown in Fig. 2, lanes 5 and 6, respectively.

measles and the onset of these CNS diseases could be explained more easily. However, our data do not support this hypothesis. MV-specific sequences were detected only in patients with acute measles and one healthy control donor. In all other RNA samples derived from PBMCs of healthy control donors and patients with SSPE or autoimmune diseases no unequivocally identifiable MV-specific signals were detectable with our method.

In contrast to our data Fournier et al. (1985) using in situ hybridization found MV-infected PBMCs in healthy adults with the frequency of $0.5-5 \%$, in young children $10-15 \%$, and in SSPE patients up to $75 \%$. However, on the basis of our detection level of one infected cell within 20,000 PBMCs, representing a frequency of $0.005 \%$ of infected cells, we could not confirm this observation neither for healthy controls nor for SSPE patients. In addition, we could not detect any differences using either PBMCs freshly isolated or stored as frozen. In the healthy control donor the expression frequency for genomic RNA of about 0.06 copies per cells was determined. Based on data published by us previously (Cattaneo et al., 1987) that an MV-infected Hela cell contains about 700 copies of genomic RNA, our hybridization experiment would suggest that one out of 12,000 cells would be infected in this case. In all other samples in which MV RNA could not be detected unequivocally, the copy numbers or infection frequency would be even at least three times lower. Similar negative data were observed by Hyypia and coworkers (1985) using dot blot hybridization in their attempts to find any MV-specific signals in total RNA derived from PBMCs of 16 healthy control donors. In order to rule out the possibility that positive and negative strand virus specific RNA might be present in almost equimolar amounts and be undetectable in our liquid hybridization assay since the longer unlabeled minus strand might compete out the excess of labeled RNA probe, in situ hybridization experiments were performed which did not reveal any convincing hybridization signals clearly discernible from background (data not shown). Moreover, PCR analysis of our test samples so far did not yield positive results since amplification of cDNA copied from cytoplasmic RNA sequences

$\begin{array}{llllllll}1 & 2 & 3 & 4 & 5 & 6 & 78\end{array}$

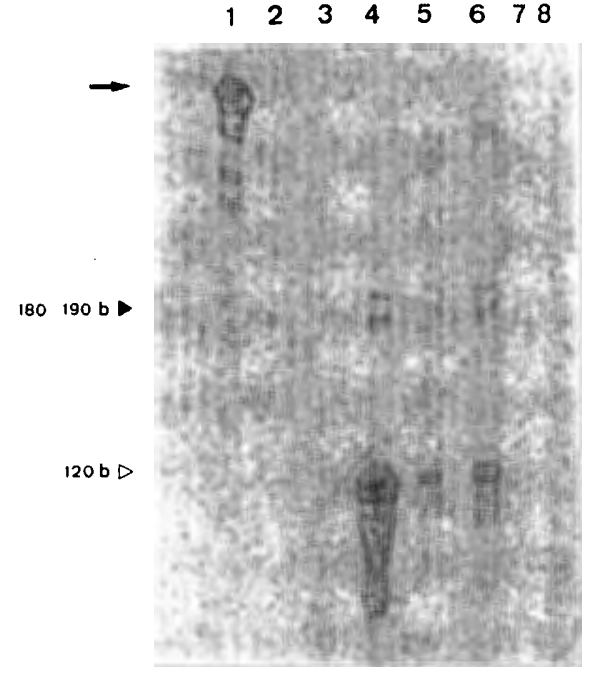

FIG. 2. Positive strand $\mathrm{N}$-gene-specific transcripts RNA derived from PBMCs from patients with acute measles, SSPE, and autoimmune diseases. Nuclease protection assay with each $5 \mu \mathrm{g}$ of RNA derived from PBMCs of patients with SLE (lane 3), acute measles (lanes 5 and 6), and SSPE (lanes 7 and 8). Lanes 1, 2, and 4 represent controls including undigested M13-probe (for description see Fig. 1c) (lane 1), digested with S1-nuclease (lane 2), and hybridized to $1 \mu \mathrm{g}$ of total RNA from lytically infected Vero cells (lane 4). As probe, the $\mathrm{M} 13 \mathrm{mp} 9 / 32 \mathrm{ssDNA}$ described in Fig. $1 \mathrm{c}$ was used. Positions are indicated for the probe (arrow), the 185-nt leader-containing (black triangle) and the 120-nt leader-free (open triangle) transcript. The double band for the 185-nt transcript (lanes 4-6) represents an artifact of the nuclease digestion. 
a

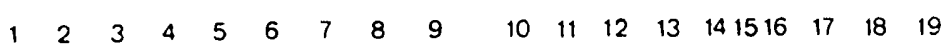

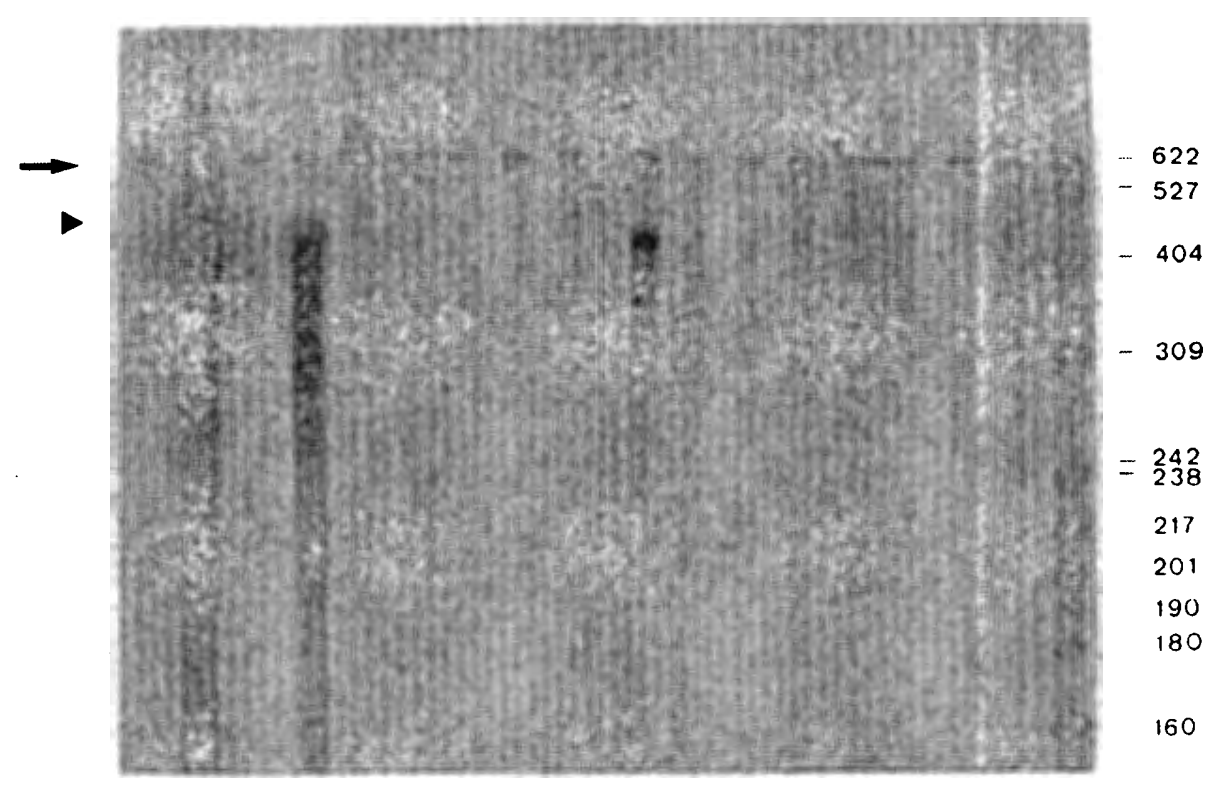

b

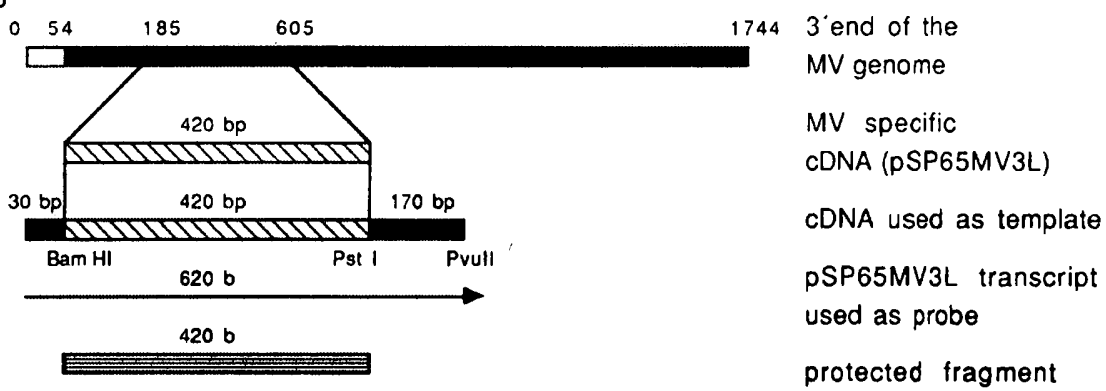

FIG. 3. MV genomic transcripts in RNA samples from PBMCs of patients with SSPE, acute measles, autoimmune diseases, and healthy controls. SP6 protection assay using a labeled RNA transcript complementary to nt $185-605$ (BamHI/Pstl fragment) of the N-gene-specific genomic sequence. For transcription, the vector ( $\mathrm{SSP} 65 \mathrm{MV} 3 \mathrm{~L}$ ) was linearized with Pvull in order to elongate the probe by unspecific sequences that could be digested by $S 1$ nuclease (see (b)). (a) Hybridization was performed with each $5 \mu g$ of total RNA derived from a newborn nonvaccinated individual (lane 3), patients with SSPE (lanes 5-9), acute measles (lanes 10-13), and SLE (lanes 17 and 18). As controls, the undigested probe (lane 1) was hybridized to $100 \mathrm{ng}$ of the complementary PSP64MV3L transcript (lane 2) and to $5 \mu \mathrm{g}$ of minus pA-RNA derived from the brain of a patient with SSPE (lane 4). The position of the specific signal for the genomic RNA is indicated by a black triangle, and the position of the probe is indicated by the arrow. As marker, pBr322/Hpall was used. (b) Localization and orientation of the MV-specific transcripts used as probes or synthetic unlabeled RNA transcripts. At the top, the $3^{\prime}$-end of the MV genome is indicated encompassing the leader sequence of $54 \mathrm{nt}$ (nt 0-54) and the entire $\mathrm{N}$-gene sequence (nt 54-1744). A cDNA clone covering a 420-bp-long BamHI/Pstl fragment within the $\mathrm{N}$-gene sequence was introduced into the pSP64 or pSP65 vector, thereby allowing to obtain transcripts of either positive (pSP65MV3L) or negative (pSP64MV3L) orientation (hatched box). The expected size of the protected fragment corresponds to the length of the MV-specific fragment (420 bp). In order to distinguish signals due to an incomplete digestion of the probe from the expected protected fragments, the pSP65MV $3 \mathrm{~L}$ vector was linearized with Pvull prior to transcription thereby elongating the probe by $170 \mathrm{nt}$ complementary to vector sequences $3^{\prime}$ to the multiple cloning site (stippled box). Additionally, about $30 \mathrm{nt} 5$ ' to the MV-specific fragment were introduced by transcription of the multiple cloning site (stippled box). The total transcript obtained of about $620 \mathrm{nt}$ in length for the positive orientation is indicated.

has not yet reached higher sensitivity than the nuclease protection assays used here.

The elevated anti-MV antibody titers occurring in some patients with autoimmune diseases has given support to the hypothesis that in these disorders few circulating lymphocytes may be persistently infected with measles virus. In this context, Robertson and coworkers (1987) carried out dot blot hybridization with oligonucleotides complementary to MV N-gene using RNA from PBMCs of different autoimmune diseases. 
With this technique these authors in contrast to our study found some positive signals in patients with chronic active hepatitis, lupus erythematosis, and cryptogenic cirrhosis. However, no detailed information is given about the sensitivity of the reaction or percentage of infected PBMCs which would allow a comparison to our data.

Replication of MV in PBMCs infected in vitro has been intensely studied (for review, see McChesney and Oldstone, 1989; Casali et al., 1989). Fewer reports are available on the presence and replication of $M V$ in PBMCs in vivo in patients with acute measles. Although the rescue of infectious virus from the PBMC fraction of patients with acute measles has been described by several authors (Gresser et al., 1963; Osunkoya et al., 1974; Sakaguchi et al., 1986) attempts to demonstrate MV specific proteins or RNA revealed conflicting results. Whereas Moench and coworkers failed to detect MV-specific proteins or RNAs by indirect immunofluorescence or in situ hybridization respectively (Moench et al., 1988), MV-specific RNA could be shown in PBMCs of patients with acute measles by nonquantitative dot blot hybridization (Hyypia et al., 1985). Our data support the presence of MVspecific transcripts in PBMCs of patients with acute measles. In support of the findings of Hyypia and coworkers the amount of MV-specific RNA detected in our experiments also varied between different samples. Our quantitative analysis, however, may not truly reflect the proportion of PBMCs infected in vivo, since viral replication and spread will have occurred in vitro upon PHA stimulation (Lucas et al., 1978). Moreover, our analysis does not provide information about the integrity or functionality of the transcripts detected. since by the nuclease protection assays only transcripts of defined lengths depending on the labeled probe used for protection are detectable. Since, however, $N$ mRNA-specific sequences are accumulating to detectable levels, active polymerase complex should be present although the concentration of the corresponding proteins may be too low to be detected by indirect immunofluorescence.

One striking finding regarding the MV transcription pattern in PBMCs of acute measles and persistently infected $B$ cells was the altered ratio between leadercontaining and leader-free $\mathrm{N}$-specific transcripts compared to the lytic infection in cells of nonlymphoid origin (Cattaneo et al., 1987). Whereas the leader-free $\mathrm{N}$-specific transcript definitely represents mRNA, the leader-containing transcript could either represent antigenome or mono- or bicistronic transcripts of the $\mathrm{N}$ gene (Castaneda and Wong, 1989, 1990). The probe used for our analysis does not allow to distinguish between these possibilities. Since, however, synthesis of the leader-containing subgenomic RNA species has been shown to be dependent on protein synthesis in contrast to the transcription of the leader-free RNA they have been interpreted to result from aborted attempts of antigenome transcription. Thereby, the high expression of leader-containing transcripts might indicate a switch from "active" transcription of mRNA to an increased replication of viral genomic RNA in lymphocytes. This phenomenon would provide an interesting example for cell-type-specific transcriptional regulation of MV. An attractive model for the absence of MV specific mRNAs in the presence of the genomic RNA has been described by Carter (Carter et al., 1984) for persistently MV-infected C6/SSPE cells in the presence of virus neutralizing antiviral antibodies. This phenomenon, termed antibody-induced antigenic modulation which has also been described in lymphocytes (Fujinami and Oldstone, 1984) may be one possibility to explain our findings in PBMCs isolated from patients with acute measies. However, since the altered ratio between antigenomic and subgenomic transcripts could also be shown in persistently infected $B$ cells, alternative explanations should be taken into account. One possible mechanism would be a decreased stability of virus-specific monocistronic transcripts in PBMCs. This suggestion would not only account for the altered proportion of antigenomic versus subgenomic RNA observed in PBMCs of acute measles, but could also explain why mRNA specific sequences could not be detected in PBMCs of patients with SSPE and autoimmune diseases and healthy controls.

The failure to detect MV-specific transcripts of either positive or negative orientation in part of our samples could also result from sequence variants in PBMCs leading to mismatches with the probes corresponding to the Edmonston strain sequence. The possibly mismatched hybrids would be partially digested during the nuclease assay. Furthermore, it should be mentioned that Wagner and co-workers (1988) found a dsRNAspecific RNA unwinding activity in extracts prepared from human cell lines of lymphoid origin. RNA unwinding activity has been proposed to be involved in hypermutational events of MV M-gene in vivo and in tissue culture in cells of neural origin (Cattaneo et al., 1988; Wong et al., 1989). Further analysis of MV gene expression in cells of lymphoid origin in tissue culture systems may provide important information on the mechanisms supporting MV persistence in those cells.

\section{ACKNOWLEDGMENTS}

We thank the Deutsche Forschungsgemeinschaft, Bundesministerium for Forschung und Technologie, and Schweizerische Nationalfonds for financial support. Dr. B. K. Rima and Dr. W. K. Joklik 
for helpful discussions, J. Roller and A. Schreckenberger for technical assistance, and $\mathrm{H}$. Kriesinger for typing the manuscript.

\section{REFERENCES}

Andjaparidze, O., G., Chaplygina, N. M., Bogomolova, N. N., Koptyaeva, I. B., Nevryaeva, E. G., Filimova, R. G., and Tareeva, I. E. (1989). Detection of measles virus genome in blood leucocytes of patients with certain autoimmune diseases. Arch. Virol. 105, 287-291.

Billeter M., BaczKo, K., Schmid, A., and ter Meulen, V. (1984). Cloning of DNA Corresponding to four different measles virus genomic regions. Virology 132, 149-159.

Carter M. J., Barrett, P. N., Willcocks, M. M., Koschel, K., and Ter MEULEN, V. (1984). Factors involved in measles virus persistence. In "Mechanisms of Viral Pathogenesis" (A. Kohn and P. Fuchs, Eds.), pp. 95-114. Nijhoff, The Hague.

CAsali, P., Nakamura, M., and McChesney, M. B. (1989). Immunosuppression by measles virus. In "Virus-Induced Immunosuppression" (St. Spector, M. Bendinelli, and H. Friedmann, Eds.). Plenum, London/New York.

CAstaneda, S. J., and Wong. T. C. (1989). Measles virus synthesizes both leaderless and leader-containing polyadenylated RNAs in vivo. J. Virol. 63, 2977-2986.

CAstanedA, S. J., and WONG, T. C. (1990). Leader sequence distinguishes between translatable and encapsidated measles virus RNAs. J. Virol. 64, 222-230.

Cattaneo, R., Rebmann, G., Baczko, K., ter Meulen, V., and BilLETER, M. A. (1987). Altered transcription of a defective measles virus genome derived from diseased human brain. EMBO J. 6 , 681-687.

Cattaneo, R., Schmid, A., Eschle, D., Baczko, K., ter Meulen, V., and BiLLETER M. A. (1988). Biased hypermutation and other genetic changes in defective measles virus in human brain infections. Cell 55, 255-265.

Fournier, J. G., Tardieu, M., Lebon, P., Robain, O., Ponsot, G., RoZENBLAT, S., and BOUTEILLE M. (1985). Detection of Measles Virus RNA in lymphocytes from peripheral blood and brain perivascular infiltrates of patients with subacute sclerosing panencephalitis. $N$. Engl. J. Med. 313, 910-915.

Fournier, J. G., GerfauX, J., Joret, A. M., Lebon, P., and Rozenblatt, S. (1988). Subacute sclerosing panencephalitis: Detection of measles virus sequences in RNA extracted from circulating lymphocytes. Br. Med. J. 296, 684.

Fujinami, R. S., and Oldstone, M. B. A. (1984). Antibody initiates virus persistence: Immune modulation and measles virus infection. In "Concepts in Viral Pathogenesis" (A. L. Notkins and M. B. A. Oldstone, Eds.), pp. 187-193. Springer-Verlag, New York.

Gresser, I., and CHANY, C. (1963). Isolation of measles virus trom the washed leucocytic fraction of blood. Proc. Soc. Exp. Biol. Med. $113,695-698$.
Horta-Barbosa, L., Hamilton, R., Wrttig, B., Fuccillo, D. A., and SEVER, J. L. (1979). Subacute sclerosing panencephalitis: Isolation of suppressed measles virus from lymph nodes biopsies. Science 173, 840-841.

HWPIÄ, T., KOKIAMÄKI, P., and VANIONPÄÄ, R. (1985). Replication of measles virus in human lymphocytes. J. Exp. Med. 161, 12611271.

JOSEPH, B. S., LAMPERT, P. W., and OLDSTONE, M. B. A. (1975). Replication and persistence of measles virus in defined subpopulations of human leucocytes. J. Virol. 16, 1638-1649.

lucas, C. J., Ubels-Postma, J. C., Reeze, A., and Galama, J. M. D. (1978). Activation of measles virus from silently infected human lymphocytes. J. Exp. Med. 148, 940-952.

MCChesney, M. B., and OLSTONE, M. B. A. (1989). Virus-induced immunosuppression: Infection with measles virus and human immunodeficiency virus. Adv. Immunol. 45, 335-380.

Melton, D. A., Krieg, P. A., Rebagliati, M. R., Maniatis, T., Zinn, K., and GREEN, M. R. (1984). Efficient in vitro synthesis of biologically active RNA and RNA hybridisation probes from plasmids containing a bacteriophage SP6 promoter. Nucleic Acids Res. 12, 70357056.

Moench, T. R., Griffin, D. E., Obriecht, C. R., Vaisberg, A. J., and JOHNSON, R. T. (1988). Acute measles in patients with and without neurological involvement: Distribution of measles virus antigen and RNA. J. Infect. Dis. 158, 433-442.

Osunkoya, B. O., Adeleye, G. I., Adejumo, T. A., and Salimonu, L. S. (1974). Studies on leucocyte cultures in measles. II. Detection of measles virus antigens in human leucocytes by immunofluorescence. Arch. Ges. Virusforschung 44, 323-329.

RoBertSON, D. A. F., GUY, E. C., ZhANG, S. L., and Wright, R. (1987) Persistent measles virus genome in autoimmune chronic active hepatitis. Lancet 2, 9-11.

Sakaguch, M., Yoshikawa, Y., Yamanouchi, K., Takeda, K., and SATO, T. (1986). Characteristics of fresh isolates of wild measles virus. Jpn. J. Exp. Med. 56, 61-67.

Sambrook, J., Fritsch, E. F., and Maniatis, T. (1989). "Molecular Cloning: A Laboratory Manual," Vols. 1-3. Cold Spring Harbor Laboratory, Cold Spring Harbor, NY.

Schneider-Schaulies, S., liebert, U. G., Baczko, K., Cattaneo, R., BILLETER, M., and TER MEULEN, V. (1989). Restriction of measles virus gene expression in acute and subacute encephalitis of Lewis rats. Virology 171, 525-534.

WAGNER, R. W., and NISHIKURA, K. (1988). Cell cycle expression of RNA duplex unwindase activity in mammalian cells. Mol. Cell. Biol. 8, 770-777.

Wong, T. C., ayata, M., Hirano, A., Yoshikawa, Y., Tsurnoka, H., and YAMANOUCHI, K. (1989). Generalized and localized biased hypermutation affecting the matrix gene of a measles virus strain that causes subacute sclerosing panencephalitis. J. Virol. 63, 5464-5468.

Wrosz, H., KULCZYCKI, J., LASKOWSKI, Z., MATACZ, D., and BrZOSKO W. J. (1979). Detection of measles virus antigen(s) in peripheral blood lymphocytes from patients with subacute sclerosing panencephalitis. Arch. Virol. 60, 291-297. 